\title{
VULNERABILIDADE DA ZONA COSTEIRA DA PRAIA DO PAIVA, MUNICÍPIO DO CABO DE SANTO AGOSTINHO, PERNAMBUCO, BRASIL
}

\author{
José Diniz MADRUGA FILHO
}

CCEN-UNESE / FUNESO

Tereza Cristina Medeiros de ARAÚJO

Departamento de Oceanografia da UFPE

\begin{abstract}
RESUMO
A praia do Paiva, situada no litoral sul do Estado de Pernambuco, embora faça parte de um Município da Região Metropolitana do Recife, ainda não é uma praia urbana. Dentro desta óptica, com o propósito de melhor aproveitar a zona costeira, como também alertar a população no sentido de não construir nas áreas de riscos, procurou-se caracterizar os seus setores mais vulneráveis. Para melhor classificar esses setores foi feita a sua divisão em três células, tomando-se como base a morfologia da linha de costa e a presença, ou não, de recifes. Essas células, embora apresentassem um grau baixo de vulnerabilidade, mostraram características específicas que permitiram distingui-las. Conclui-se que na área em estudo, as células 2 e 3 mostraram-se em equilíbrio durante o período monitorado, enquanto que, a célula 1 revelou-se como a mais vulnerável apresentando um balanço sedimentar negativo.

Palavras-chave : vulnerabilidade, zona costeira, praia, célula
\end{abstract}

\section{ABSTRACT \\ Vulnerability of the Coastal Zone of Paiva Beach, Cabo de Santo Agostinho, Pernambuco, Brazil}

Paiva's beach, placed in the south coast of the State of Pernambuco, although it is part of a Municipal district of the Metropolitan Area of Recife, is not yet an urban beach. In this view point optical, with the best purpose to take advantage of the coastal zone, as well as, to alert the population in the sense of not building in the areas of risks, we sought to characterize its more vulnerable sections. For to best classify those sections it was made a division in three cells, taking as base the morphology of the coast line and, the presence or not of reefs. Those cells, although they presented a low degree of vulnerabilidade, they showed specific characteristics that allowed to distinguish them. It is concluded that in the area in study, the cells 2 and 3, were shown in balance during the monitored period, while, the cell 1 was revealed as the most vulnerable presenting a negative sedimentary balance.

Key-words: vulnerability, coastal zone, beach, cell

\section{INTRODUÇÃO}

O grau de vulnerabilidade de uma zona costeira, ou mais especificamente de uma praia, é determinado em função do deslocamento da linha de costa, como também da estabilidade e das características da mesma (DAL CIN \& SIMEONI, 1994). Tal grau dimensiona a destreza com que um processo ou elemento de um sistema sofre agressões 
de agentes de impactos causando prejuízo. Em geral, a vulnerabilidade está associada ao grau de urbanização e de intervenções na zona costeira (COUTINHO et al., 1997). As praias que apresentam uma progradação ou estabilidade, com a berma alta e bem desenvolvida, declive suave para o mar, como também a presença de recifes ou de barras arenosas na antepraia, tem a área correspondente à sua retaguarda protegida.

Através da consideração dos parâmetros abordados, enquadrou-se a vulnerabilidade em uma classificação em graus, que variam do $1^{\circ}$ ao $3^{\circ}$, a saber:

1. $1^{\circ}$ grau - distingue-se por exibir praias com propensão à progradação, com póspraia e estirâncio bem desenvolvidos, e ausência de obras de contenção;

2. $2^{\circ}$ grau - a praia apresenta uma frágil estabilidade, ou ligeira propensão à erosão, exibindo ainda os setores de pós-praia e estirâncio pouco desenvolvidos e presença de obras de fixação;

3. $3^{\circ}$ grau - ausência de pós-praia, reduzido estirâncio e forte presença de estruturas de proteção.

\section{DESCRIÇÃO DA ÁREA}

A área de estudo localiza-se na Praia do Paiva, no litoral sul do Estado de Pernambuco. Pertence à Bacia Sedimentar Pernambuco (Lima Filho, 1998) e está inserida geograficamente na faixa costeira sul do referido Estado, dentro do Município do Cabo, entre os paralelos $8^{\circ} 15^{\prime} 76^{\prime}$ ' e $8^{\circ} 17^{\prime} 89^{\prime}$ ' de latitude sul, com limite a oeste no meridiano $34^{\circ} 57^{\prime} 30^{\prime}$ ' e a leste na linha de costa (Figura 1).

\section{MATERIAL E MÉTODOS}

Durante o desenvolvimento dos estudos foram realizados caminhadas, com medições e levantamento fotográfico, para melhor caracterizar o ambiente praial e registrar as possíveis mudanças ocorridas ao longo do litoral da Praia do Paiva. Foram também realizadas, no período de maio de 97 a março de 98, amostragens de sedimento em três perfis $\left(\mathrm{P}_{1}, \mathrm{P}_{2}\right.$ e $\left.\mathrm{P}_{3}\right)$ posicionados perpendicularmente em relação a linha de costa (Figura 2).

Para obtenção da altura das ondas(diferença vertical entre a crista e a cava da ondulação, medidas na zona de arrebentação) foi utilizada uma mira posicionada verticalmente na zona de espraiamento médio, localizada no estirâncio inferior. Procurando-se alinhar a crista das ondas com a linha do horizonte determinou-se a sua altura. O ângulo de incidência, formado pelo trem de ondas e a linha de costa, foi medido com uma bússola.

A metodologia utilizada para a análise granulométrica foi a de SUGUIO (!)/\#), utilizando-se um intervalo de peneiras de $1 \phi$. Os parâmetros estatísticos foram definidos através do Programa PANCOM (TOLDO JR. \& DORNELES, 1991).

\section{RESULTADOS}

No estudo da vulnerabilidade da área, baseado na morfologia da linha de costa, em função da presença ou não de recifes, foi possível distinguir três tipos de células, denominadas de células 1, 2 e 3 (Figura 2). A falta de obras de contenção, como também a presença de estirâncios bem desenvolvidos, fez com que as três células fossem enquadradas no $1^{\circ}$ grau de vulnerabilidade. Entretanto, apesar de exibirem esse 
baixo grau, todas as três células apresentam características específicas, descritas a seguir: 


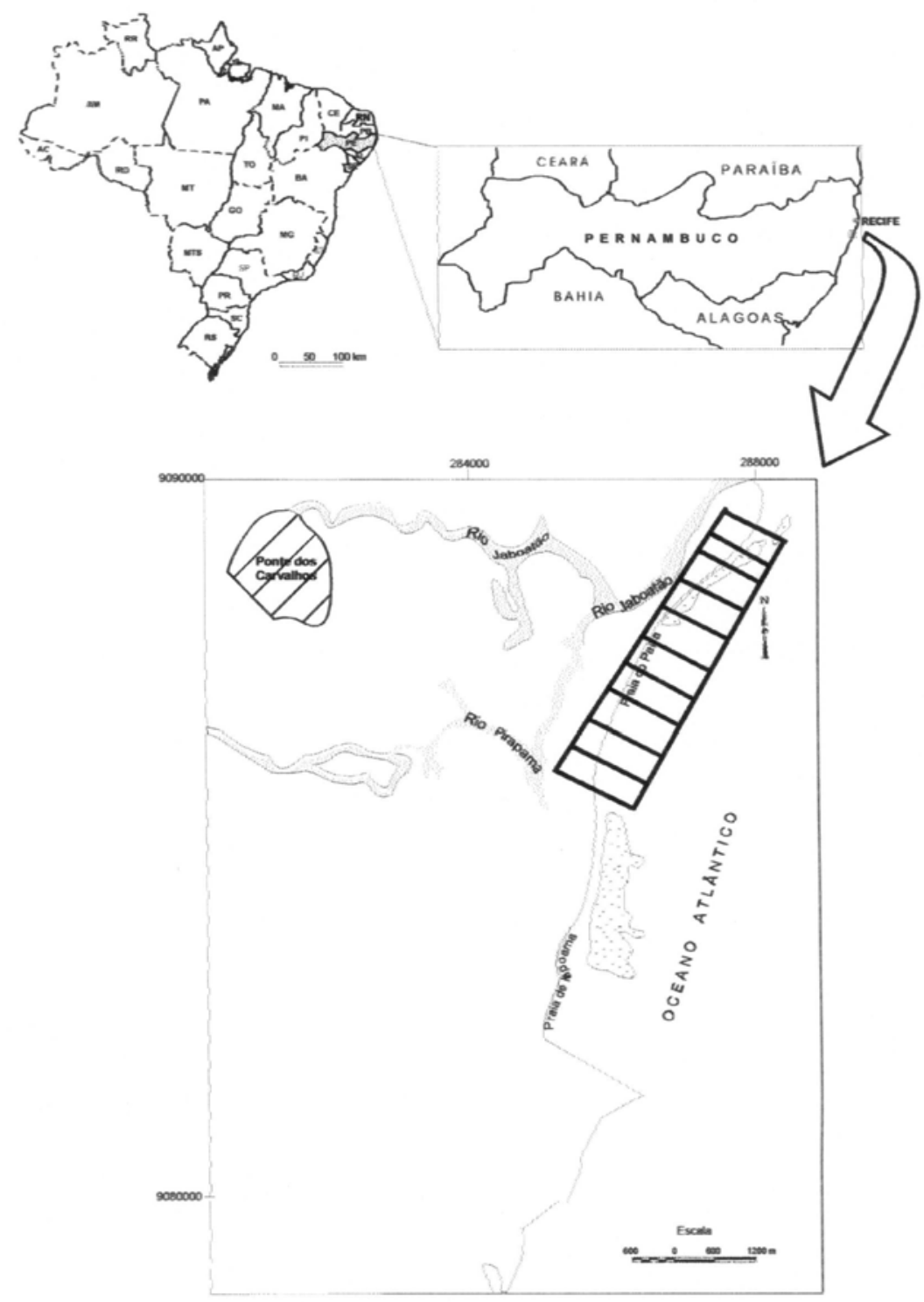

Figura 1 - Mapa de localização da área

III Área de estudo 
Célula-1 - estende-se desde o limite Norte da área, onde começam os recifes, indo até o final da primeira concavidade, com extensão de cerca de $2,5 \mathrm{~km}$. Caracteriza-se pela presença dos recifes, que representam verdadeiros anteparos naturais protegendo a linha de costa, em toda sua extensão (Fotos 1, 2 e.3). Apesar da presença de tais anteparos naturais submersos na maré alta, resguardando a linha de costa da ação das ondas e construções, posicionados adequadamente, (sem interferir nas inter-relações entre o mar e a costa), ser indicativo de um relativo equilíbrio, esta célula foi a que se mostrou mais vulnerável, durante o período monitorado. Nos meses em que ocorrem as maiores marés, nota-se que as ondas sobrepõem os recifes e atingem a linha de costa. Há, então, acúmulo ou retirada de sedimentos. Alguns recifes, com fraca diagênese, ficam expostos, com a retirada do material testemunhando o transporte local. Os sedimentos, no período monitorado, podem ser classificados como areia média, moderadamente selecionada, no setor de pós-praia. Na praia, os mesmos variaram desde areia média até fina, com predominância da média. Por fỉm, na antepraia, ocorreu uma variação sazonal com areias, variando de grossa a cascalho (junho a setembro de 97) e areias, muito fina a fina (outubro de 97 a março de 98).

Célula-2 - estende-se do final da célula 1, até um certo setor constituído por terras úmidas (Foto 3). Caracteriza-se por apresentar uma linha de costa onde se observa coqueiros, com as raízes expostas, prestes a desabar (Foto 4). Os recifes aparecem nesta célula em uma extensão de $500 \mathrm{~m}$ a partir do seu limite Norte, estando o restante da mesma exposta a mar aberto. As ondas apresentam altura média de 1,12m sendo em sua grande maioria do tipo deslizantes. O seu ângulo de incidência, com a linha de costa, é de $0^{\circ}$. A faixa de praia tem em torno de $40 \mathrm{~m}$, com declividade média de $5^{\circ}$. A pós-praia é, até certo ponto, larga, coberta por coqueiros, vegetação rasteira e, terras úmidas no seu limite Sul. A escarpa praial desta célula varia, tendo em média 1,60m, podendo, contudo, atingir 2,0m (Foto 4). Os sedimentos podem ser classificados como areia média, de bem a moderadamente selecionada, no setor de pós-praia e praia. $\mathrm{Na}$ antepraia, encontra-se uma predominância de uma areia fina ou muito fina variando, entre pobremente a moderadamente selecionada. As poucas casas existentes, encontram-se bastantes recuadas em relação à linha de berma. No período de observação, a célula como um todo, manteve-se aparentemente em equilíbrio (MADRUGA FILHO, 1999). Os indícios de processos erosivos, evidenciados pelas raízes de coqueiros expostas, permaneceram, a princípio, inalterados durante $\mathrm{o}$ monitoramento.

Célula-3 - estende-se do final da célula 2, em um setor constituído por terras úmidas, até a cerca de troncos de coqueiros, que divide as praias do Paiva e Itapoama (Fotos 3 e 6). Caracteriza-se por exibir uma faixa de praia superior à célula 2 ( $45 \mathrm{~m}$ em média) e, uma escarpa praial inferior, decrescendo de Norte para Sul. A declividade da praia porém, permaneceu a mesma. As ondas apresentam altura média de $1,14 \mathrm{~m}$, superior a célula 2 , entretanto, são também, em sua grande maioria, do tipo deslizantes. $\mathrm{O}$ ângulo de incidência das mesmas com a linha de costa, comportou-se como na célula anterior (frontal). A pós-praia, também, assemelha-se à célula dois, sendo coberta por coqueiros, vegetação rasteira, entretanto, as terras úmidas não aparecem. 


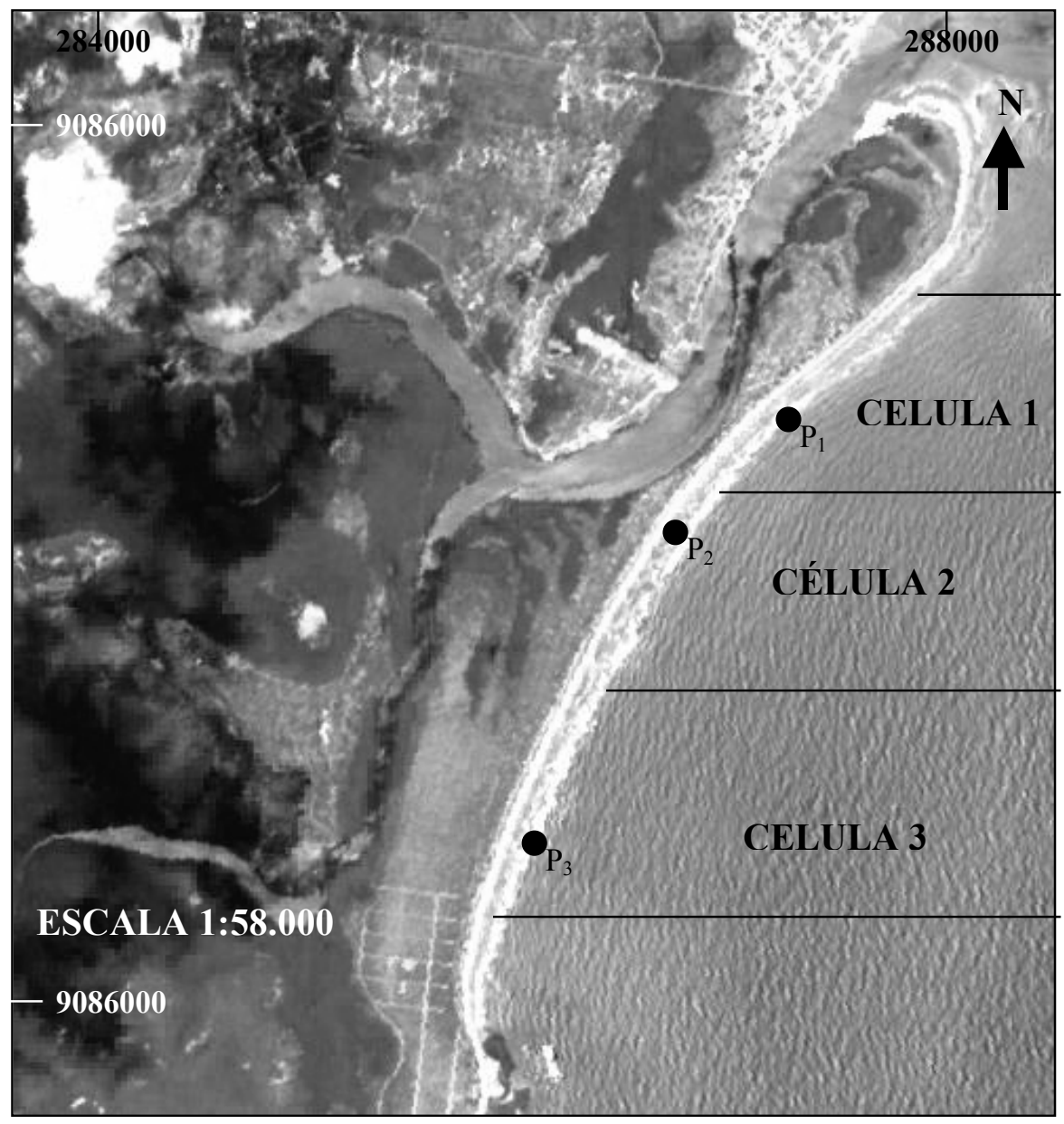

Figura 2 - Imagem de satélite (SPOT PANCROMÁTICA/LANDSAT superposição e imagem), mostrando as células da área de estudo, suas características morfológicas e os perfis praiais.

Legenda: - Perfis praiais da área. 


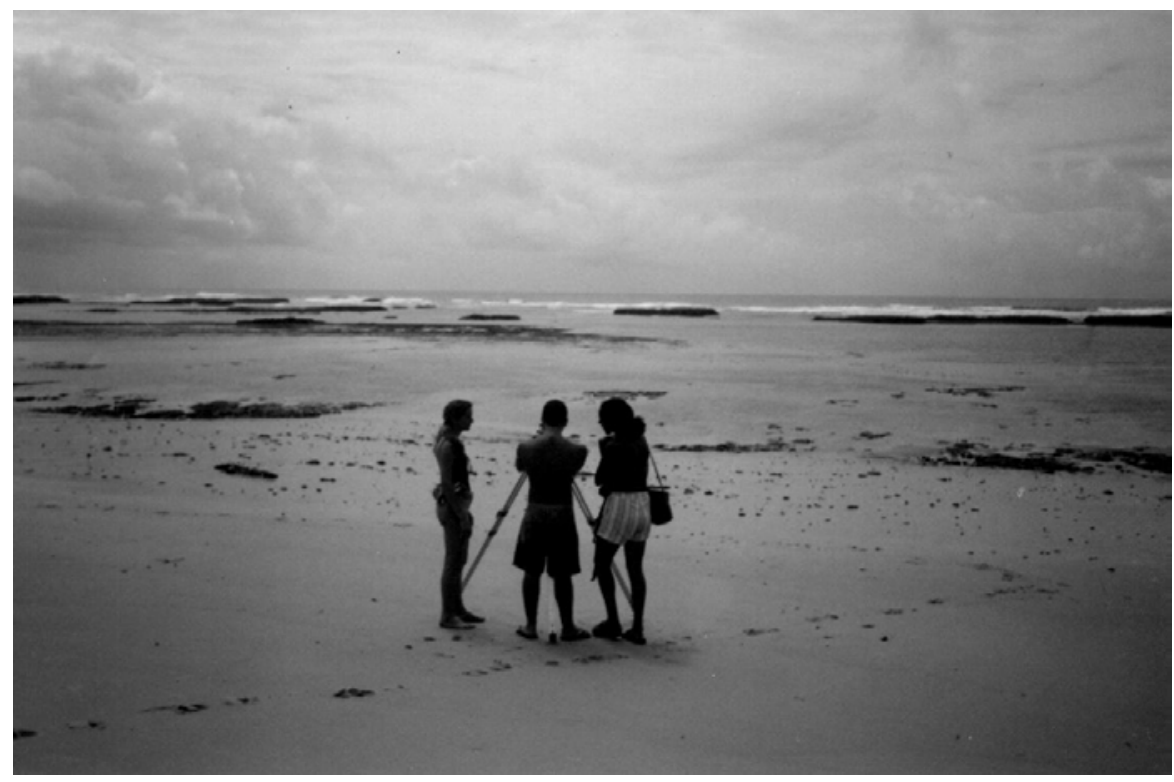

Foto 1 - Vista parcial da célula 1, mostrando os recifes 


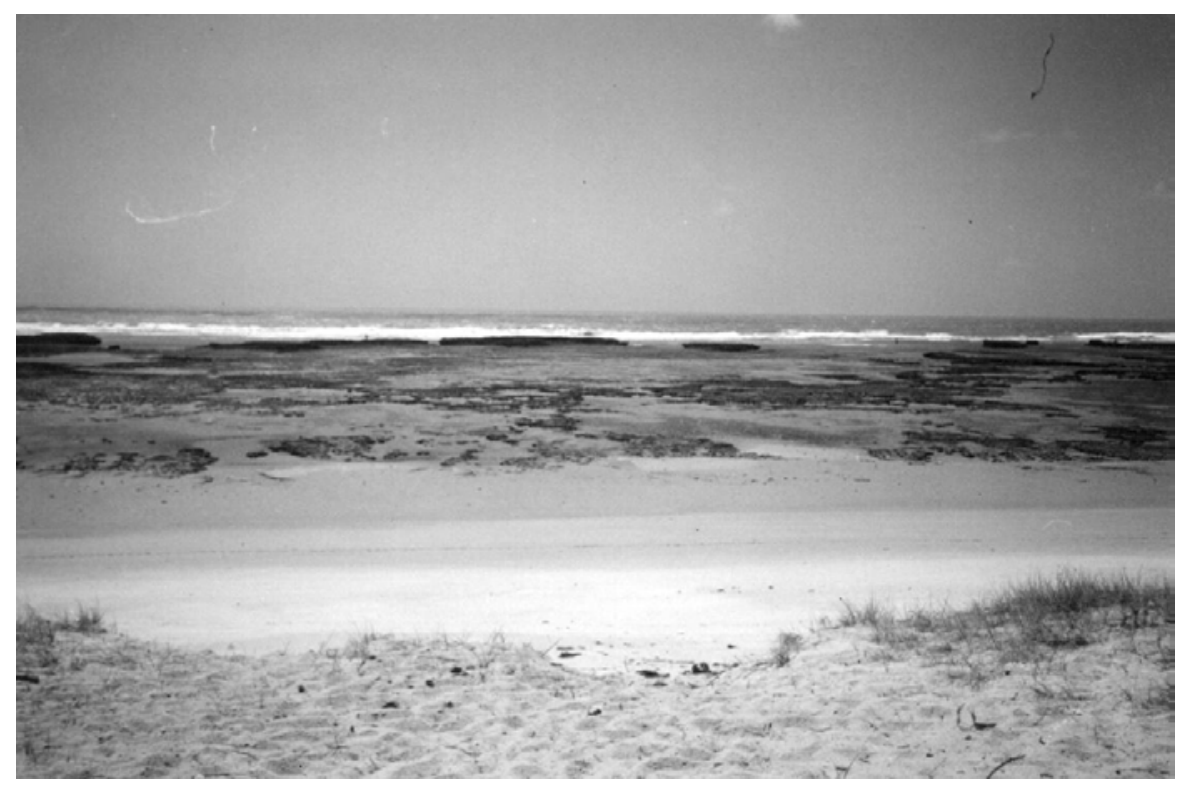

Foto 2 - Vista dos recifes da célula 1, em maior detalhe.

Foto 3 - Vista da divisa entre a célula 2 (à esquerda) e 3.

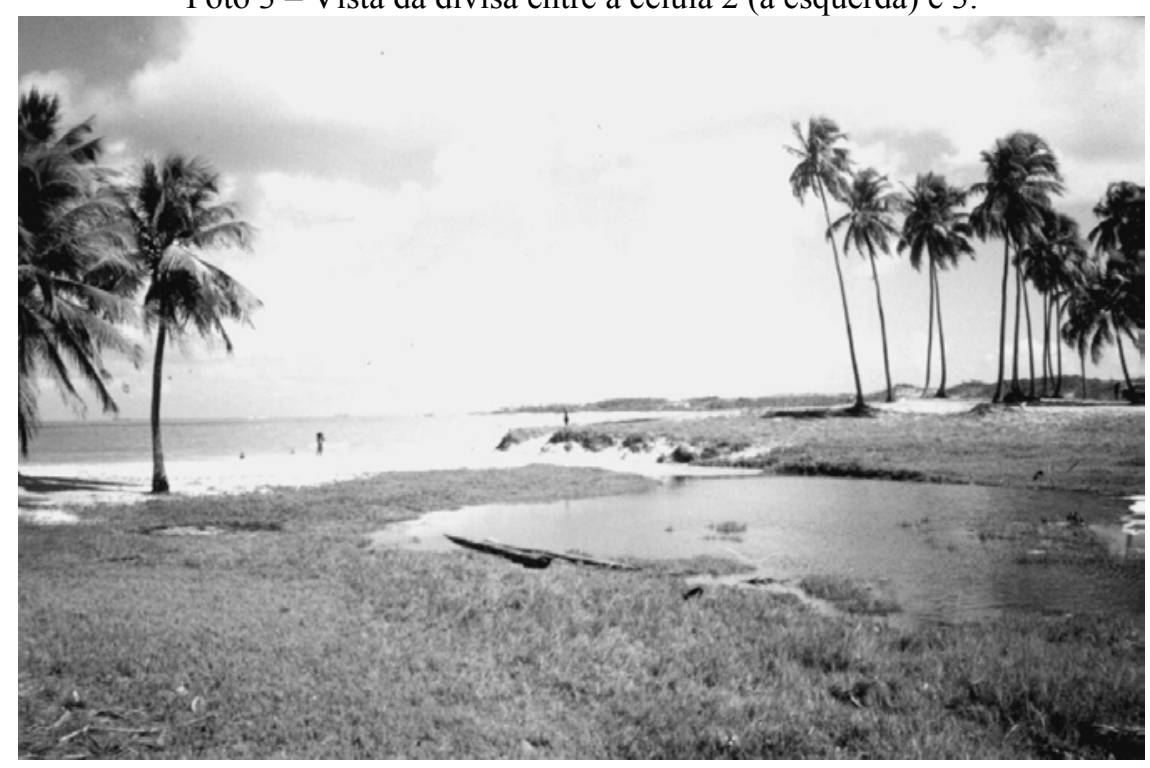




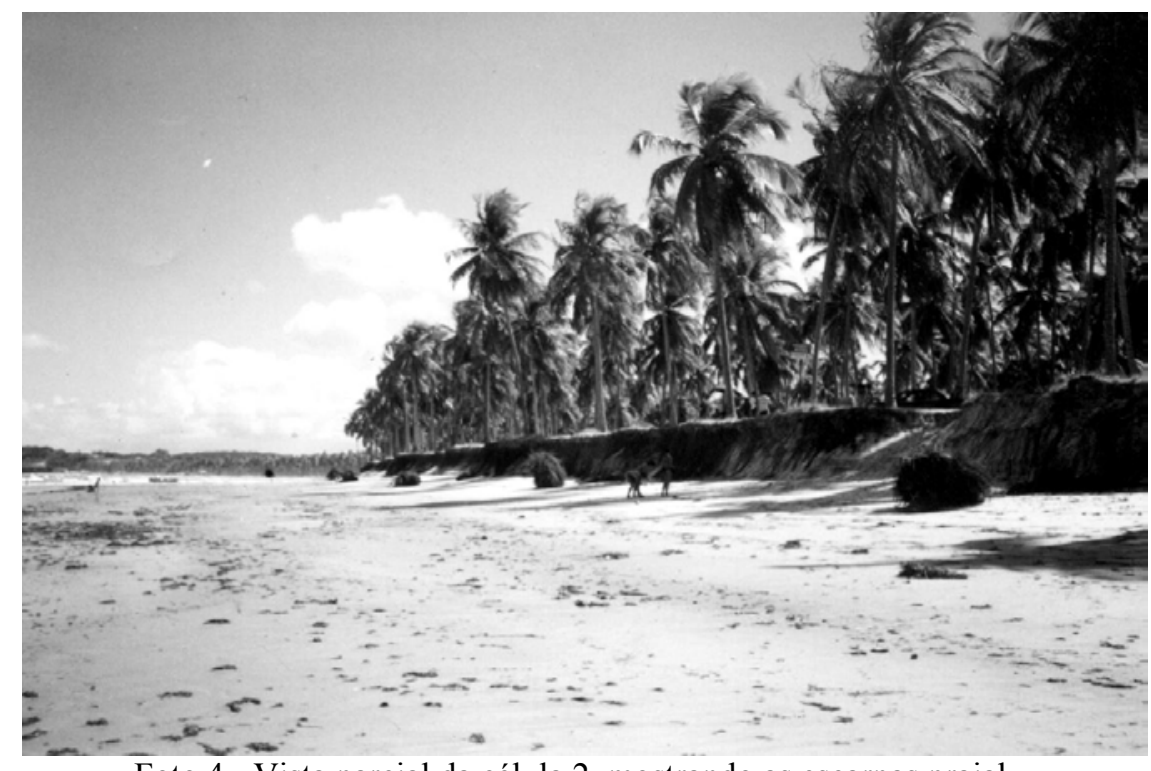

Foto 4 - Vista parcial da célula 2, mostrando as escarpas praial.

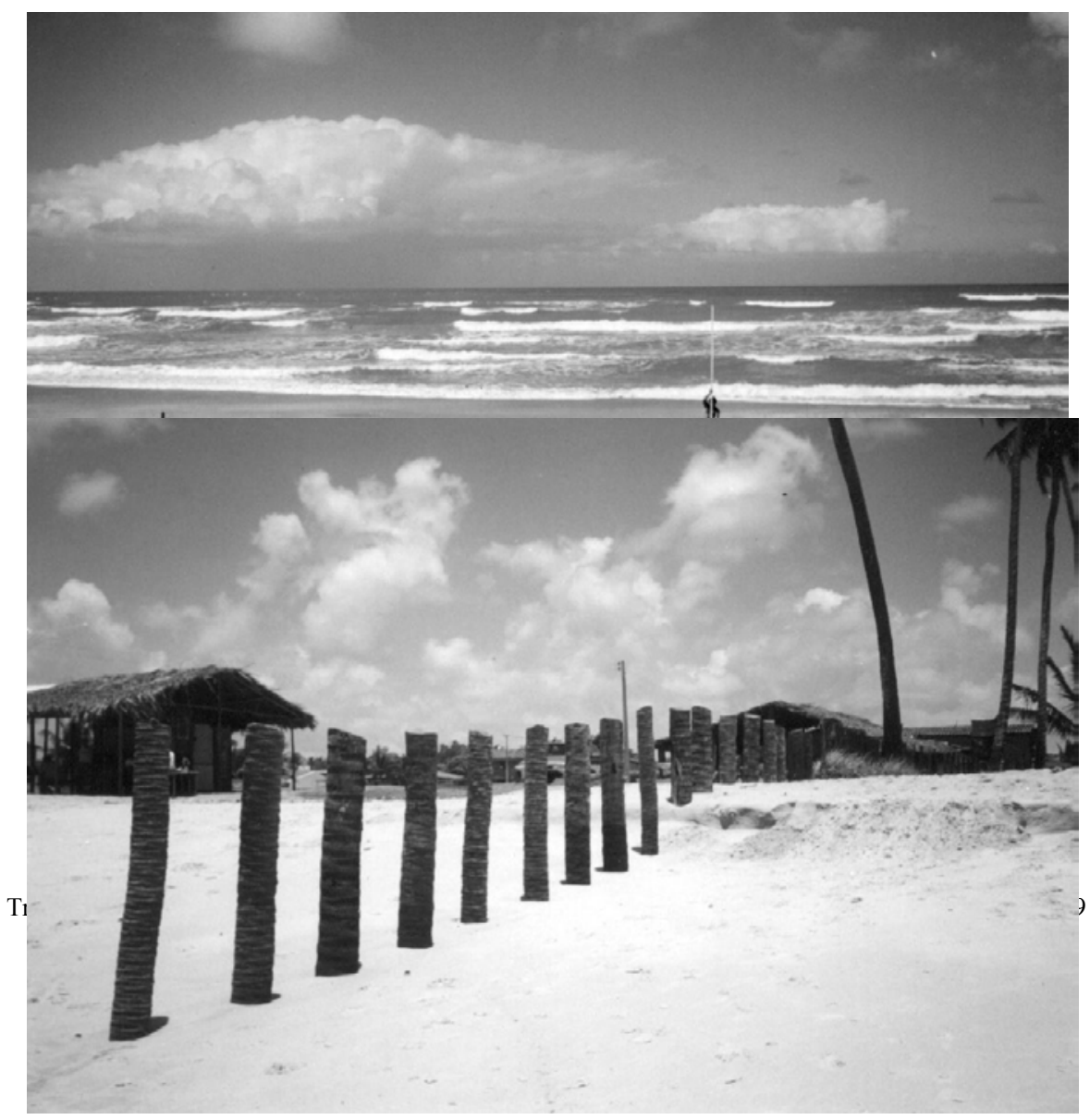


Os sedimentos, deste setor, podem ser classificados como areia média, moderadamente selecionada. Já na praia e antepraia (Foto 5), encontrou-se uma areia fina, nos meses de setembro a novembro de 97, e areia média no restante dos meses. Esta célula, durante o período de monitoramento, manteve-se aparentemente em equilíbrio. Em abril/98, após a conclusão dos trabalhos de campo, em uma maré alta, ocorreu uma grande remoção de sedimentos, na faixa de praia, deixando expostos troncos de coqueiros, aparentemente fixos ao chão e alinhados com as linhas de coqueiros atuais.

\section{DISCUSSÃO E CONCLUSÃO}

Baseado na morfologia da linha de costa, em função da presença ou não de recifes, pôde-se distinguir na praia do Paiva, três tipos de células denominadas: células 1,2 , e 3 que, embora apresentassem um grau baixo de vulnerabilidade, mostraram características específicas que permitiram distingui-las. $\mathrm{Na}$ área em estudo, as células 2 e 3, mostraram-se em equilíbrio durante o período monitorado. A célula 1, revelou-se como a mais vulnerável apresentando um balanço sedimentar negativo. Isto talvez possa ser justificado analisando-se o perfil $\mathrm{P}_{1}$, na figura 2, posicionado nesta célula, que está localizado em uma área bastante crítica e que apresentou um déficit de sedimento no período estudado. Pode-se constatar também, um pontal em formação e um estuário bastante degradado. É provável que o pontal, já referido, esteja se formando através dos sedimentos transportados pelo estuário de Barras de Jangadas, em concomitância com o material proveniente do déficit sedimentar da célula 1 (MADRUGA FILHO, 1999). Para um melhor entendimento da vulnerabilidade da praia do Paiva, recomenda-se a não construção e um acompanhamento dos trechos em que se constatou indícios de processos erosivos, com balanço sedimentar negativo.

\section{REFERÊNCIAS BIBLIOGRÁFICAS}

COUTINHO, P.N.; LIMA, A.T.O; QUEIROZ, C.M.; FREIRE, G.S.S.; ALMEIDA, L.E.S.B.; MAIA, L.P.; MANSO, V.A. V.; BORBA, AL. S.; MARTINS, M.H.A.; \& DUARTE, R.X., 1997. Estudo da erosão marinha nas praias de Piedade e de Candeias e no estuário de Barra de Jangadas. Município de Jaboatão dos Guararapes-PE. Laboratório de Geologia e Geofísica Marinha-LGGM/UFPE. Realatório Técnico. 154 p. + 3 mapas em anexo.

DALCIN, R., SIMEONI, U. - 1994 - A model for determinig the classification, vulnerability bad risk in the southern coastal zone of the Marche (Italy). Journal of Coastal Research, 10 (1), 18-29 
LIMA FILHO, M.F., 1998. Análise estratigráfica e estrutural da Bacia Pernambuco. Tese de Doutoramento. Programa de Pós-Graduação em Geoquímica e Geotectônica, Universidade de São Paulo - Instituto de Geociências, São Paulo, p.2-20.

MADRUGA FILHO,J.D.,1999. Estudos sedimentológicos morfodinâmicos e hidrodinâmicos na praia do Paiva município do Cabo de Santo Agostinho - PE. Programa de Pós - graduação em Geociências, Universidade Federal de Pernambuco - Centro de Tecnologia e Geociências, Recife - PE

SUGUIO, K., 1973. Introdução à Sedimentologia. São Paulo: Ed. Edgard Blücher Ltda. São Paulo. 318p.

TOLDO JR., E.E. \& DORNELLES, C.E., 1991. Programa de Análise Completa (PANCOM). Sistema de Análise Granulométrica (ECD). Pesquisas. Instituto de Geociências/UFRGS. 